\title{
HYBIRD CRYPTOSYSTEM ALGORITMA HILL CIPHER DAN ALGORITMA ELGAMAL PADA KEAMANAN CITRA
}

\author{
Suci Ramadani
}

STMIK Kaputama, Binjai, Indonesia

Email: suci.ramadani23@gmail.com

DOI: https://doi.org/10.46880/jmika.Vol4No1.pp1-9

\begin{abstract}
ABSTRAK
Perkembangan Teknologi pada saat ini memungkinkan setiap orang untuk saling bertukar informasi tanpa ada batasan waktu dan jarak. Kemungkinan yang akan terjadi adanya kebocoran data pada saat proses pertukaran informasi yang dilakukan, oleh karena itu dalam pengiriman data khususnya citra, aspek keamanan, kerahasiaan dan efesiensi penyimpanan data sangat diperlukan. Jika informasi penting tersebut jatuh ke tangan orang yang salah, maka akan menyebabkan hal yang tidak diinginkan, contohnya manipulasi gambar dengan bentuk yang negatif dan dapat merugikan pemilik gambar. Salah satu metode yang digunakan untuk menjaga keamanan data tersebut adalah kriptografi dengan menggunakan salah satu teknik yaitu Elgamal. Kekuatan algoritma ini terletak pada sulitnya menghitung algoritma diskrit pada bilangan bulat prima yang didalamnya dilakukan operasi pekalian. Dalam penelitian ini, penulis menggabungkan antara Hill Cipher untuk melakukan penyandian enkripsi citra dan Algoritma Elgamal untuk mendekripsi kunci dari Hill Cipher. Citra pertama kali dienkripsi menggunakan Hill Cipher, kemudian kunci Hill Cipher tersebut dienkripsi dengan menggunakan Algoritma Elgamal. Implementasi sistem menggunakan bahasa pemograman Visual Basic Net 2010. Hasil implementasi dengan citra awal dienkrip memiliki waktu 4282.85 Milidetik dengan hasil gambar yang beracak-acak sedangkan citra yang sudah dienkrip akan kembali di deskripsikan yang memiliki waktu 20442.84 Milidetik dengan hasil citra kembali ke awal.
\end{abstract}

Kata Kunci: Kriptografi, Simetris, Beasiswa, Hill Cipher, Elgamal

\section{PENDAHULUAN}

Keamanan dan kerahasiaan citra merupakan salah satu aspek yang sangat penting dalam sistem informasi pada saat ini. Disebabkan pesatnya perkembangan ilmu pengetahuan dan teknologi yang memungkinkan munculnya teknik-teknik baru, yang disalah gunakan oleh pihak-pihak tertentu yang mengancam keamanan dari sistem informasi tersebut. Jatuhnya informasi ke tangan pihak lain dapat menimbulkan kerugian bagi pemilik informasi. Salah satu cara yang dapat dilakukan untuk pengamanan citra adalah diantaranya menggunakan algoritma Hill Cipher dan algoritma Elgamal.

Algoritma Hill Cipher dan algoritma Elgamal bertujuan untuk menjaga kerahasiaan informasi yang terkandung dalam citra sehingga informasi tersebut tidak dapat diketahui oleh pihak yang tidak sah. Beragam algoritma kriptografi dibuat untuk mengamankan suatu citra. Dalam beberapa penelitian sebelumnya telah dibahas mengenai kriptografi, antara lain: Implementasi Algoritma Hill Cipher Dalam Penyandian Data (Abdul Halim Hasugian, 2013), Perancangan Aplikasi Keamanan Pesan Menggunakan
Algoritma Elgamal Dengan Memanfaatkan Algoritma One Time Pad Sebagai Pembangkit Kunci (Achmad Fauzi, dkk., 2017) dan Pengamanan Data dengan Kombinasi Teknik Kriptografi Rabin dan Teknik Steganografi Chaotic LSB (Jamaluddin, dkk., 2018). Berdasarkan uraian di atas, maka penulis melakukan penelitian dengan judul "Hybird Cryptosystem Algoritma Hill Cipher dan Algoritma Elgamal Pada Pengamanan Citra".

\section{LANDASAN TEORI \\ Kriptografi}

Kriptografi (Cryptography) berasal dari Bahasa Yunani yaitu "cryptos" yang artinya "secret" (rahasia) dan "graphein" yang artinya "writing" (menulis). Jadi kriptografi berarti "secret writing" (tulisan rahasia).

\section{Hybrid Cryptosystem}

Menurut penelitian tentang Hybrid Cryptosystem (H. Agung) Hybrid Cryptosystem yaitu kombinasi kriptografi dgn menggabungkan algoritma simetris dan algoritma asimetris atau dengan public key dan private key. Karena kelebihan dan 
kekurangan yang ada pada masing-masing algoritma simetris dan algoritma asimetris, maka tidaklah benar bahwa kriptografi kunci asimetris menggantikan kriptografi kunci simetris.

\section{Algoritma Hill Cipher}

Algoritma kriptografi atau cipher, dan juga sering disebut dengan istilah sandi adalah suatu fungsi matematis yang digunakan untuk melakukan enkripsi dan dekripsi Ada dua macam algoritma kriptografi, yaitu algoritma simetris (symmetric algorithms) dan algoritma asimetris (asymmetric algorithms). Hill cipher yang merupakan polyalphabetic cipher dapat dikategorikan sebagai block cipher, (Pardede, 2014) karena teks yang akan diproses akan dibagi menjadi blok-blok dengan ukuran tertentu. Setiap karakter dalam satu blok akan saling mempengaruhi karakter lainnya dalam proses enkripsi dan dekripsinya, sehingga karakter yang sama tidak dipetakan menjadi karakter yang sama pula Arya Widyanarko (2009 h. 231).

\section{METODE PENELITIAN}

Masalah yang akan diselesaikan dengan menggunakan system ini adalah pengamanan berupa citra. Dalam perancangan system pengkodean citra yang akan diimplementasikan dengan algoritma hill cipher dan algoritma elgamal, terlebih dahulu dilakukan analisa mengenai bentuk system yang akan dirancang.

\section{Analisis Perhitungan Enkripsi Citra Dengan} Algoritma Hill Cipher

Pada proses enkripsi Hill Cipher mempunyai panjang maksimal penentuan bilangan, langkah selanjutnya mengubah citra kedalam bilangan haxedesimal yang diurutkan kedalam bentuk matriks 3x3 dan dilakukan analisis enkripsi pada algoritma Hill Cipher yang bertujuan untuk mengubah citra asli (plaintext) ke bentuk citra yang rahasia (ciphertext) (Pardede, 2018).

Proses file gambar matriks $3 \times 3$ tersebut adalah:

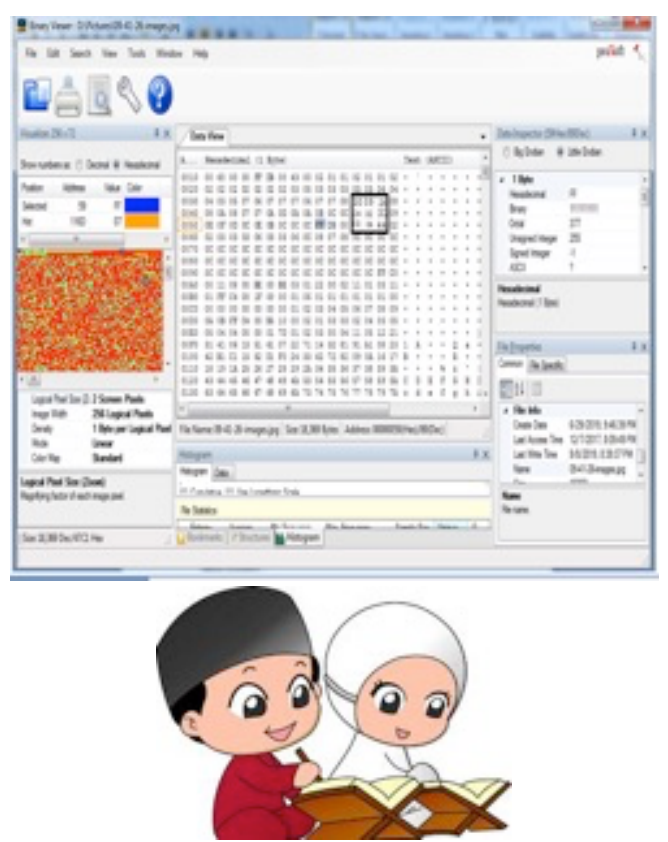

Gambar 1. Citra Format .jpg

Maka proses dekripsi citra dengan algoritma Hill Cipher sebagai berikut:

\begin{tabular}{lllllll}
\multicolumn{4}{l}{ pixel $(0,0)=$ Red $=53$, Green $=28$, Blue $=67$} \\
212 & 140 & 3 & & 53 & 253 \\
33 & 34 & 166 & x & $28=255$ & \\
0 & 63 & 8 & & 67 &
\end{tabular}

pixel $(0,1)=\operatorname{Red}=53$, Green $=28$, Blue $=67$

$\begin{array}{lllll}212 & 140 & 3 & 53 & 253\end{array}$

$33 \quad 34 \quad 166 \times 28=255$

$\begin{array}{llllll}0 & 63 & 8 & 67 & 252\end{array}$

pixel $(0,2)=\operatorname{Red}=27$, Green $=52$, Blue $=153$

$\begin{array}{llllcccc}212 & 140 & 3 & & 27 & 151 \\ 33 & 34 & 166 & \times & 52 \quad= & 153 \\ 0 & 63 & 8 & & 153 & 148 & \end{array}$

pixel $(0,3)=$ Red $=179$, Green $=220$, Blue $=225$

$\begin{array}{lllll}212 & 140 & 3 & 179 & 47\end{array}$

$33 \quad 34 \quad 166 \times 220=49$

$\begin{array}{lllll}0 & 63 & 8 & 225 & 44\end{array}$

\begin{tabular}{|c|c|c|c|c|c|c|}
\hline 212 & 140 & 3 & & 48 & & 56 \\
\hline 33 & 34 & 166 & X & 41 & $=$ & 58 \\
\hline 0 & 63 & 8 & & 4 & & 55 \\
\hline \multicolumn{7}{|c|}{ pixel $(0,5)=\operatorname{Red}=68$, Green $=245$, Blue $=0$} \\
\hline 212 & 140 & 3 & & 68 & & 76 \\
\hline 32 & 34 & 166 & $X$ & 245 & $=$ & 78 \\
\hline & 63 & 8 & & 0 & & 75 \\
\hline
\end{tabular}


pixel $(0,6)=$ Red $=82$, Green $=170$, Blue $=53$

$\begin{array}{llllrll}212 & 140 & 3 & & 82 & & 127 \\ 33 & 34 & 166 & \times & 170 & = & 132 \\ 0 & 63 & 8 & & 53 & & 126\end{array}$

pixel $(0,7)=\operatorname{Red}=222$, Green $=214$, Blue $=61$

$\begin{array}{llllrlrl}212 & 140 & 3 & & 222 & & 151 \\ 33 & 34 & 166 & \times & 214 \\ 0 & 63 & 8 & & 61 & & & 152 \\ & & & & & & & \end{array}$

pixel $(0,8)=\operatorname{Red}=16$, Green $=110$, Blue $=221$

$\begin{array}{llllccc}212 & 140 & 3 & & 16 & & 255 \\ 33 & 34 & 166 & \times & 110 & = & 250 \\ 0 & 63 & 8 & & 221 & & 250\end{array}$

pixel $(0,9)=$ Red $=103$, Green $=235$, Blue $=101$

$\begin{array}{llllccc}212 & 140 & 3 & & 103 & 255 \\ 33 & 34 & 166 & \times & 235 \\ 0 & 63 & 8 & & 101 & & 251 \\ 0 & & & & & & \end{array}$

pixel $(0,10)=\operatorname{Red}=122$, Green $=89$, Blue $=195$

$\begin{array}{llllll}212 & 140 & 3 & & 122 & 253 \\ 33 & 34 & 166 & \times & 89= & 254 \\ 0 & 63 & 8 & & 195 & 255\end{array}$

pixel $(0,11)=\operatorname{Red}=237$, Green $=1$, Blue $=184$

$\begin{array}{llllclll}212 & 140 & 3 & & 237 & 248 & \\ 33 & 34 & 166 & \mathrm{x} & 1 & = & 255 \\ 0 & 63 & 8 & & 184 & 255 & \end{array}$

\begin{tabular}{lllllll}
\multicolumn{4}{l}{ pixel } & $(0,12)=$ Red $=161$, Green $=145$, Blue $=202$ \\
212 & 140 & 3 & 161 & 254 & \\
33 & 34 & 166 & $x$ & 145 & $=$ & 255 \\
0 & 63 & 8 & 202 & 255 &
\end{tabular}

pixel $(0,13)=\operatorname{Red}=109$, Green $=83$, Blue $=114$

$\begin{array}{lllll}212 & 140 & 3 & 109 & 254\end{array}$

$\begin{array}{llllll}33 & 34 & 166 & \times & 83 & =\end{array}$

$\begin{array}{lllll}0 & 63 & 8 & 114 & 253\end{array}$

pixel $(0,14)=$ Red $=197$, Green $=174$, Blue $=229$

$\begin{array}{lllll}212 & 140 & 3 & 197 & 251\end{array}$

$\begin{array}{llllll}33 & 34 & 166 & \times & 174 & =\end{array}$

$\begin{array}{lllll}0 & 63 & 8 & 229 & 250\end{array}$

pixel $(1,0)=$ Red $=139$, Green $=107$, Blue $=117$

$\begin{array}{lllll}212 & 140 & 3 & 139 & 255\end{array}$

$\begin{array}{lllll}33 & 34 & 166 & \times & 107\end{array}$

$\begin{array}{lllll}0 & 63 & 8 & 117 & 253\end{array}$

pixel $(1,1)=\operatorname{Red}=61$, Green $=105$, Blue $=107$

$\begin{array}{llll}212 & 140 & 3 & 6149\end{array}$ $\begin{array}{lllll}33 & 34 & 166 \times & 105=\end{array}$

49

$\begin{array}{lllll}0 & 63 & 8 & 107 & 47\end{array}$

pixel $(1,2)=$ Red $=89$, Green $=88$, Blue $=111$

$\begin{array}{lllll}212 & 140 & 3 & 89 & 33\end{array}$

$\begin{array}{llllll}33 & 34 & 166 & \times & 88 & =\end{array}$

$\begin{array}{lllll}0 & 63 & 8 & 111 & 32\end{array}$

pixel $(1,3)=\operatorname{Red}=18$, Green $=75$, Blue $=23$

$\begin{array}{lllll}212 & 140 & 3 & 18 & 49\end{array}$

$33 \quad 34 \quad 166 \times 75=50$

$\begin{array}{lllll}0 & 63 & 8 & 23 & 45\end{array}$

pixel $(1,4)=\operatorname{Red}=37$, Green $=173$, Blue $=84$

$\begin{array}{llll}212 & 140 & 3 & 3760\end{array}$

$33 \quad 34 \quad 166 \times 173=55$

$\begin{array}{llll}0 & 63 & 8 & 8451\end{array}$

pixel $(1,5)=\operatorname{Red}=11$, Green $=82$, Blue $=191$

$\begin{array}{llll}212 & 140 & 3 & 1149\end{array}$

$\begin{array}{lllllll}33 & 34 & 166 & \mathrm{x} & 82 & = & 41\end{array}$

$\begin{array}{llll}0 & 63 & 8 & 19138\end{array}$

pixel $(1,6)=\operatorname{Red}=168$, Green $=184$, Blue $=23$

$\begin{array}{lllll}212 & 140 & 3 & 1685\end{array}$

$\begin{array}{lllllll}33 & 34 & 166 & \times & 184 & =\end{array}$

$\begin{array}{lllll}0 & 63 & 8 & 23 & 0\end{array}$

pixel $(1,7)=\operatorname{Red}=208$, Green $=50$, Blue $=63$

$\begin{array}{llll}212 & 140 & 3 & 20885\end{array}$

$\begin{array}{llllll}33 & 34 & 166 & \times & 50 & =\end{array}$

$\begin{array}{lllll}0 & 63 & 8 & 6370\end{array}$

pixel $(1,8)=\operatorname{Red}=200$, Green $=212$, Blue $=15$

$\begin{array}{llll}212 & 140 & 3 & 200189\end{array}$

$33 \quad 34 \quad 166 \times 212=170$

$\begin{array}{llll}0 & 63 & 8 & 15164\end{array}$

pixel $(1,9)=\operatorname{Red}=120$, Green $=198$, Blue $=196$

$\begin{array}{lllll}212 & 140 & 3 & 120 & 244\end{array}$

$33 \quad 34 \quad 166 \times 198=220$

$\begin{array}{lllll}0 & 63 & 8 & 196 & 218\end{array}$

pixel $(1,10)=$ Red $=33$, Green $=109$, Blue $=5$

$\begin{array}{lllll}212 & 140 & 3 & 33 & 255\end{array}$

$\begin{array}{llllll}33 & 34 & 166 & \times & 109 & =\end{array}$

$\begin{array}{lllll}0 & 63 & 8 & 5 & 251\end{array}$

pixel $(1,11)=$ Red $=67$, Green $=107$, Blue $=85$

$\begin{array}{lllll}212 & 140 & 3 & 67 & 255\end{array}$

$\begin{array}{llllll}33 & 34 & 166 & \times & 107 & =\end{array}$

$\begin{array}{lllll}0 & 63 & 8 & 85 & 253\end{array}$ 


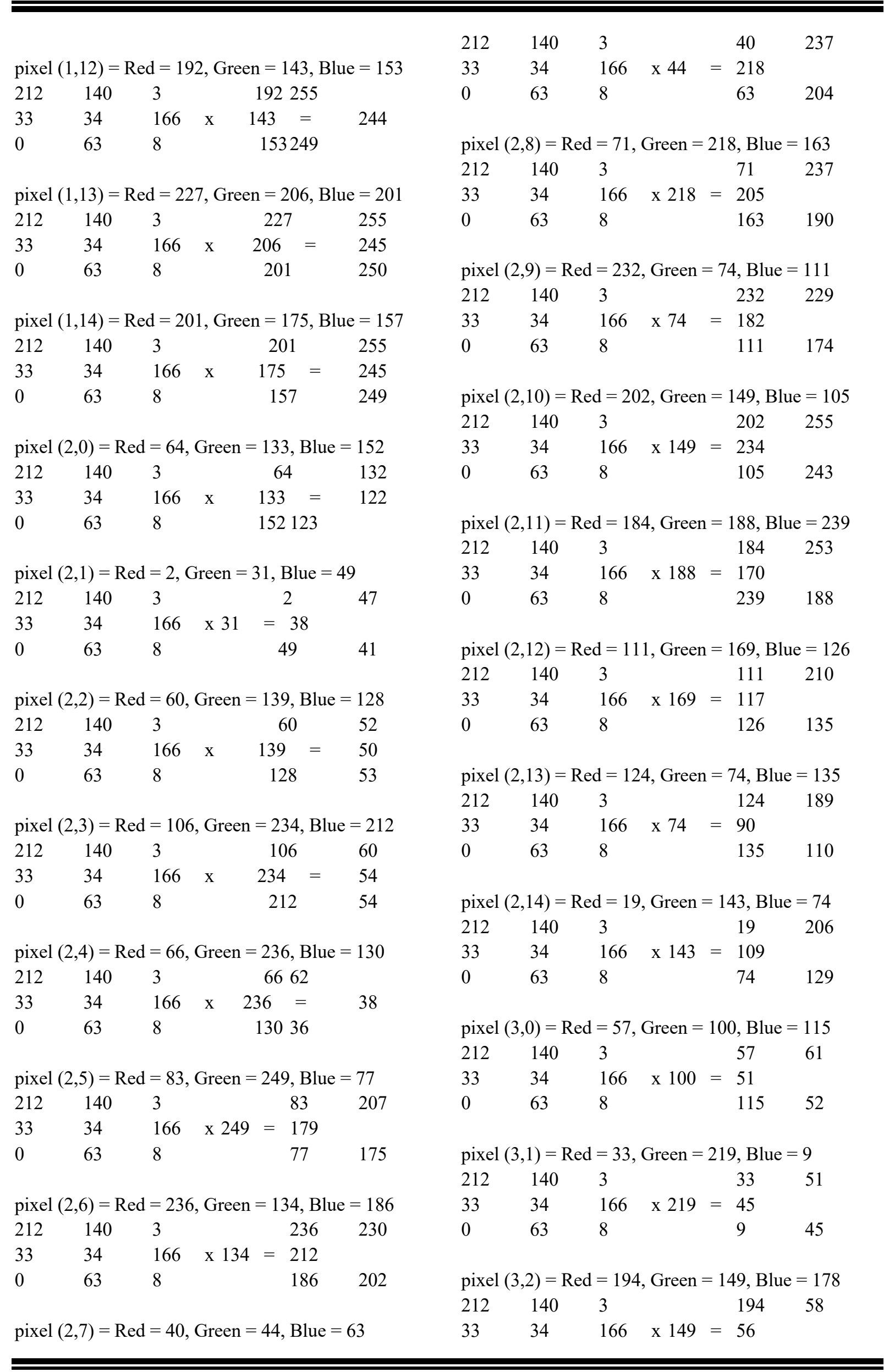


$\begin{array}{lllll}0 & 63 & 8 & 178 & 59\end{array}$

pixel $(3,3)=\operatorname{Red}=9$, Green $=130$, Blue $=231$

$\begin{array}{llllll}212 & 140 & 3 & & 9 & 65 \\ 33 & 34 & 166 & \times 130= & 55 & \\ 0 & 63 & 8 & & 231 & 54\end{array}$

pixel $(3,4)=$ Red $=148$, Green $=243$, Blue $=179$

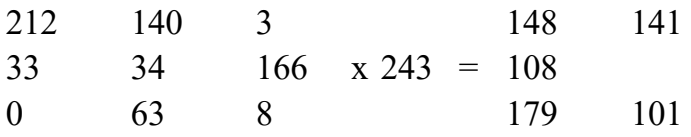

pixel $(3,5)=\operatorname{Red}=83$, Green $=118$, Blue $=53$

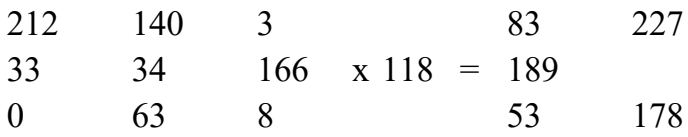

pixel $(3,6)=\operatorname{Red}=124$, Green $=169$, Blue $=70$

$\begin{array}{llllll}212 & 140 & 3 & & 124 & 238 \\ 33 & 34 & 166 & \text { x } 169= & 210 & \\ 0 & 63 & 8 & & 70 & 199\end{array}$

pixel $(3,7)=\operatorname{Red}=158$, Green $=194$, Blue $=155$

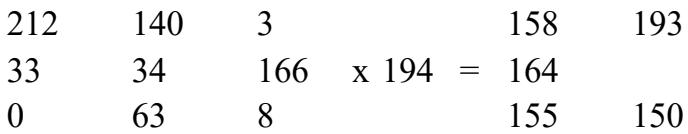

pixel $(3,8)=\operatorname{Red}=147$, Green $=238$, Blue $=5$

\begin{tabular}{|c|c|c|c|}
\hline 140 & 3 & & 147 \\
\hline 34 & 166 & x 238 & $=205$ \\
\hline 63 & 8 & & 5 \\
\hline
\end{tabular}

pixel $(3,9)=\operatorname{Red}=179$, Green $=14$, Blue $=9$

\begin{tabular}{|c|c|c|c|}
\hline 140 & 3 & & 179 \\
\hline 34 & 166 & x 14 & $=197$ \\
\hline 63 & 8 & & 9 \\
\hline
\end{tabular}

pixel $(3,10)=\operatorname{Red}=6$, Green $=172$, Blue $=121$

$\begin{array}{lllll}212 & 140 & 3 & 6 & 115\end{array}$

$33 \quad 34 \quad 166 \times 172=20$

$\begin{array}{lllll}0 & 63 & 8 & 121 & 28\end{array}$

pixel $(3,11)=\operatorname{Red}=245$, Green $=12$, Blue $=6$

$\begin{array}{lllll}212 & 140 & 3 & 245 & 134\end{array}$

$33 \quad 34 \quad 166 \times 12=17$

$\begin{array}{lllll}0 & 63 & 8 & 6 & 36\end{array}$

pixel $(3,12)=$ Red $=120$, Green $=121$, Blue $=172$

$\begin{array}{lllll}212 & 140 & 3 & 120 & 144\end{array}$

$33 \quad 34 \quad 166 \times 121=18$

$\begin{array}{lllll}0 & 63 & 8 & 172 & 39\end{array}$

\begin{tabular}{llllll}
\multicolumn{4}{c}{ pixel $(3,13)=$ Red $=248$, Green $=$} & \multicolumn{3}{c}{84, Blue $=220$} \\
212 & 140 & 3 & & 248 & 148 \\
33 & 34 & 166 & x $184=$ & 16 & \\
0 & 63 & 8 & & 220 & 40
\end{tabular}

pixel $(3,14)=$ Red $=103$, Green $=229$, Blue $=90$

$\begin{array}{lllll}212 & 140 & 3 & 103 & 150\end{array}$

$33 \quad 34 \quad 166 \times 229=13$

$\begin{array}{lllll}0 & 63 & 8 & 90 & 43\end{array}$

pixel $(4,0)=\operatorname{Red}=148$, Green $=249$, Blue $=125$

$\begin{array}{lllll}212 & 140 & 3 & 148 & 51\end{array}$

$33 \quad 34 \quad 166 \times 249=52$

$\begin{array}{lllll}0 & 63 & 8 & 125 & 47\end{array}$

pixel $(4,1)=\operatorname{Red}=225$, Green $=139$, Blue $=160$

$\begin{array}{lllll}212 & 140 & 3 & 225 & 56\end{array}$

$33 \quad 34 \quad 166 \times 139=55$

$\begin{array}{lllll}0 & 63 & 8 & 160 & 53\end{array}$

pixel $(4,2)=\operatorname{Red}=146$, Green $=179$, Blue $=38$

$\begin{array}{lllll}212 & 140 & 3 & 146 & 62\end{array}$

$33 \quad 34 \quad 166 \times 179=60$

$\begin{array}{lllll}0 & 63 & 8 & 38 & 61\end{array}$

pixel $(4,3)=\operatorname{Red}=101$, Green $=204$, Blue $=99$

$\begin{array}{lllrrr}212 & 140 & 3 & & 101 & 93 \\ 33 & 34 & 166 & \text { x 204 } & 79 & \\ 0 & 63 & 8 & & 99 & 76\end{array}$

pixel $(4,4)=$ Red $=4$, Green $=148$, Blue $=135$

$\begin{array}{lllll}212 & 140 & 3 & 4 & 213\end{array}$

$33 \quad 34 \quad 166 \times 148=182$

$\begin{array}{lllll}0 & 63 & 8 & 135 & 164\end{array}$

pixel $(4,5)=$ Red $=26$, Green $=253$, Blue $=174$

$\begin{array}{lllll}212 & 140 & 3 & 26 & 238\end{array}$

$33 \quad 34 \quad 166 \times 253=200$

$\begin{array}{lllll}0 & 63 & 8 & 174 & 179\end{array}$

pixel $(4,6)=\operatorname{Red}=19$, Green $=85$, Blue $=211$

$\begin{array}{lllll}212 & 140 & 3 & 19 & 177\end{array}$

$33 \quad 34 \quad 166 \times 85=143$

$\begin{array}{lllll}0 & 63 & 8 & 211 & 131\end{array}$

pixel $(4,7)=$ Red $=213$, Green $=192$, Blue $=101$

$\begin{array}{lllll}212 & 140 & 3 & 213 & 147\end{array}$

$33 \quad 34 \quad 166 \times 192=115$

$\begin{array}{lllll}0 & 63 & 8 & 101 & 104\end{array}$ 


$$
\begin{aligned}
& \text { pixel }(4,8)=\text { Red }=213 \text {, Green }=212 \text {, Blue }=48 \\
& \begin{array}{lllll}
212 & 140 & 3 & 213 & 228
\end{array} \\
& 33 \quad 34 \quad 166 \times 212=189 \\
& \begin{array}{lllll}
0 & 63 & 8 & 48 & 172
\end{array} \\
& \text { pixel }(4,9)=\text { Red }=36 \text {, Green }=187 \text {, Blue }=244
\end{aligned}
$$

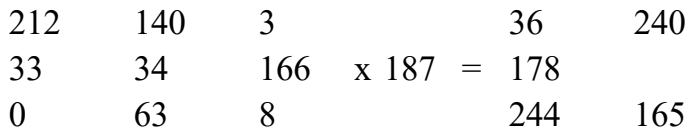

$$
\begin{aligned}
& \text { pixel }(4,10)=\operatorname{Red}=216, \text { Green }=161, \text { Blue }=46 \\
& \begin{array}{lllll}
212 & 140 & 3 & 216 & 118
\end{array} \\
& 33 \quad 34 \quad 166 \times 161=14 \\
& \begin{array}{lllll}
0 & 63 & 8 & 46 & 15
\end{array}
\end{aligned}
$$$$
\text { pixel }(4,11)=\operatorname{Red}=128, \text { Green }=87 \text {, Blue }=88
$$$$
\begin{array}{lllll}
212 & 140 & 3 & 128 & 156
\end{array}
$$$$
33 \quad 34 \quad 166 \times 87=30
$$$$
\begin{array}{lllll}
0 & 63 & 8 & 88 & 41
\end{array}
$$$$
\text { pixel }(4,12)=\operatorname{Red}=7 \text {, Green }=83 \text {, Blue }=119
$$$$
\begin{array}{lllll}
212 & 140 & 3 & 7 & 149
\end{array}
$$$$
33 \quad 34 \quad 166 \times 83=23
$$$$
\begin{array}{lllll}
0 & 63 & 8 & 119 & 37
\end{array}
$$$$
\text { pixel }(4,13)=\operatorname{Red}=204, \text { Green }=207 \text {, Blue }=39
$$$$
\begin{array}{lllll}
212 & 140 & 3 & 204 & 153
\end{array}
$$$$
33 \quad 34 \quad 166 \times 207=20
$$$$
\begin{array}{lllll}
0 & 63 & 8 & 39 & 41
\end{array}
$$$$
\text { pixel }(4,14)=\text { Red }=64, \text { Green }=23, \text { Blue }=177
$$$$
\begin{array}{lllll}
212 & 140 & 3 & 64 & 167
\end{array}
$$$$
33 \quad 34 \quad 166 \times 23=20
$$$$
\begin{array}{lllll}
0 & 63 & 8 & 177 & 49
\end{array}
$$$$
\text { pixel }(5,0)=\text { Red }=83, \text { Green }=206 \text {, Blue }=189
$$$$
\begin{array}{lllll}
212 & 140 & 3 & 83 & 155
\end{array}
$$$$
33 \quad 34 \quad 166 \times 206=157
$$$$
\begin{array}{lllll}
0 & 63 & 8 & 189 & 154
\end{array}
$$$$
\text { pixel }(5,1)=\operatorname{Red}=32, \text { Green }=185 \text {, Blue }=212
$$$$
\begin{array}{lllll}
212 & 140 & 3 & 32 & 40
\end{array}
$$$$
33 \quad 34 \quad 166 \times 185=42
$$$$
\begin{array}{lllll}
0 & 63 & 8 & 212 & 39
\end{array}
$$

pixel $(5,2)=$ Red $=170$, Green $=219$, Blue $=238$

$\begin{array}{lllll}212 & 140 & 3 & 170 & 86\end{array}$

$33 \quad 34 \quad 166 \times 219=84$

\begin{tabular}{|c|c|c|c|c|c|}
\hline 212 & 140 & 3 & & & 16 \\
\hline 33 & 34 & 166 & x 71 & $=$ & 212 \\
\hline 0 & 63 & 8 & & & 73 \\
\hline
\end{tabular}

$\begin{array}{lllll}0 & 63 & 8 & 238 & 85\end{array}$

pixel $(5,3)=\operatorname{Red}=192$, Green $=126$, Blue $=43$

$\begin{array}{lllll}212 & 140 & 3 & 192 & 105\end{array}$
$33 \quad 34 \quad 166 \times 126=94$

90

$\begin{array}{lllll}0 & 63 & 8 & 43\end{array}$

pixel $(5,4)=\operatorname{Red}=16$, Green $=71$, Blue $=73$

pixel $(5,5)=\operatorname{Red}=224$, Green $=99$, Blue $=106$

$\begin{array}{lllll}212 & 140 & 3 & 224 & 226\end{array}$

$\begin{array}{llll}33 & 34 & 166 & \times 99=194\end{array}$

$\begin{array}{lllll}0 & 63 & 8 & 106 & 173\end{array}$

pixel $(5,6)=\operatorname{Red}=91$, Green $=254$, Blue $=133$

$\begin{array}{lllll}212 & 140 & 3 & 91 & 211\end{array}$

$33 \quad 34 \quad 166 \times 254=181$

$\begin{array}{lllll}0 & 63 & 8 & 133 & 170\end{array}$

pixel $(5,7)=\operatorname{Red}=250$, Green $=251$, Blue $=224$

$\begin{array}{lllll}212 & 140 & 3 & 250 & 236\end{array}$

\begin{tabular}{|c|c|c|c|c|c|}
\hline 212 & 140 & 3 & & 49 & 229 \\
\hline 33 & 34 & 166 & x 48 & $=179$ & \\
\hline 0 & 63 & 8 & & 91 & 168 \\
\hline
\end{tabular}

$33 \quad 34 \quad 166 \times 251=208$

$\begin{array}{lllll}0 & 63 & 8 & 224 & 197\end{array}$

pixel $(5,8)=\operatorname{Red}=1$, Green $=180$, Blue $=41$

$\begin{array}{lllll}212 & 140 & 3 & 1 & 191\end{array}$

$33 \quad 34 \quad 166 \times 180=159$

$\begin{array}{lllll}0 & 63 & 8 & 41 & 148\end{array}$

pixel $(5,9)=\operatorname{Red}=49$, Green $=48$, Blue $=91$

pixel $(5,10)=\operatorname{Red}=110$, Green $=211$, Blue $=113$

$\begin{array}{lllll}212 & 140 & 3 & 110 & 207\end{array}$

$33 \quad 34 \quad 166 \times 211=122$

$\begin{array}{lllll}0 & 63 & 8 & 113 & 117\end{array}$

pixel $(5,11)=\operatorname{Red}=40$, Green $=19$, Blue $=175$

$\begin{array}{lllll}212 & 140 & 3 & 40 & 145\end{array}$

$33 \quad 34 \quad 166 \times 19=40$

$\begin{array}{lllll}0 & 63 & 8 & 175 & 37\end{array}$

pixel $(5,12)=\operatorname{Red}=155$, Green $=233$, Blue $=153$

$\begin{array}{lllll}212 & 140 & 3 & 155 & 147\end{array}$

$33 \quad 34 \quad 166 \times 233=35$

$\begin{array}{lllll}0 & 63 & 8 & 153 & 31\end{array}$

pixel $(5,13)=\operatorname{Red}=249$, Green $=120$, Blue $=145$

$\begin{array}{lllll}212 & 140 & 3 & 249 & 135\end{array}$

$33 \quad 34 \quad 166 \times 120=15$

$\begin{array}{lllll}0 & 63 & 8 & 145 & 16\end{array}$ 


\begin{tabular}{|c|c|c|c|c|c|}
\hline 212 & 140 & 3 & & 157 & 145 \\
\hline 33 & 34 & 166 & x 162 & $=11$ & \\
\hline 0 & 63 & 8 & & 167 & 22 \\
\hline
\end{tabular}

Sampai Perhitungan tesebut mencapai pixel ke $(14,14)$

pixel $(14,14)=\operatorname{Red}=152$, Green $=65$, Blue $=118$

$\begin{array}{lll}212 & 140 & 3 \\ 33 & 34 & 166 \\ 0 & 63 & 8\end{array} \quad$ x $65=\begin{array}{rr}152 & 206 \\ 190 & \\ 118 & 175\end{array}$

Perancangan Proses

Dalam perancangan aplikasi citra ini penulis menggunakan metode algoritma Hill Cipher dan algoritma Elgamal dalam menyelesaikan masalah.

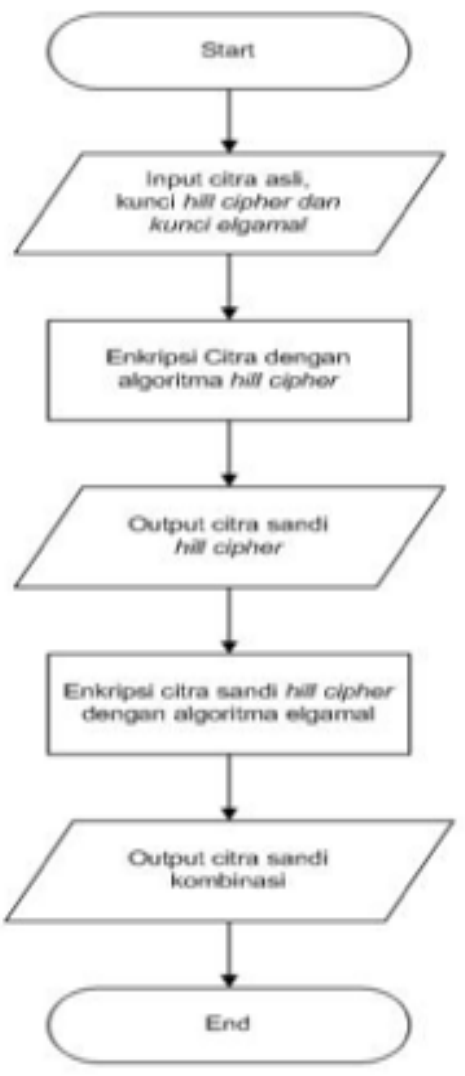

Gambar 2. Flowchart Enkripsi

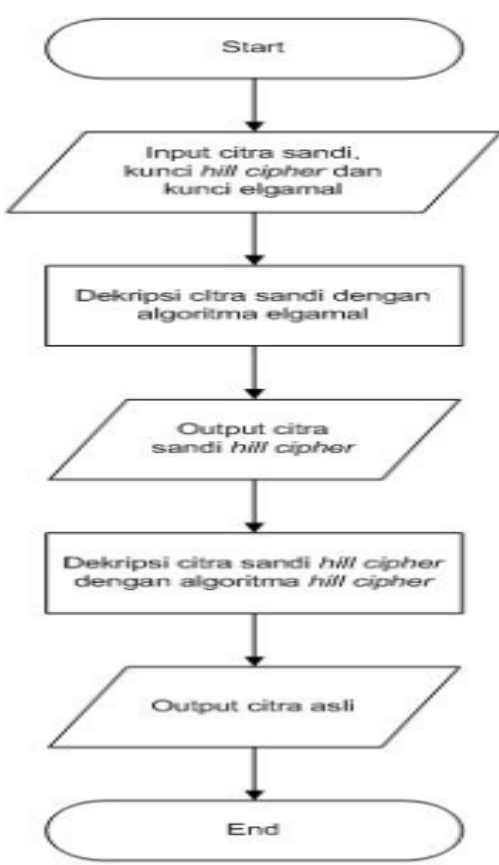

Gambar 3. Flowchart Dekripsi

\section{Activity Diagram}

Berikut merupakan gambaran dari Activity diagram untuk enkripsi citra :

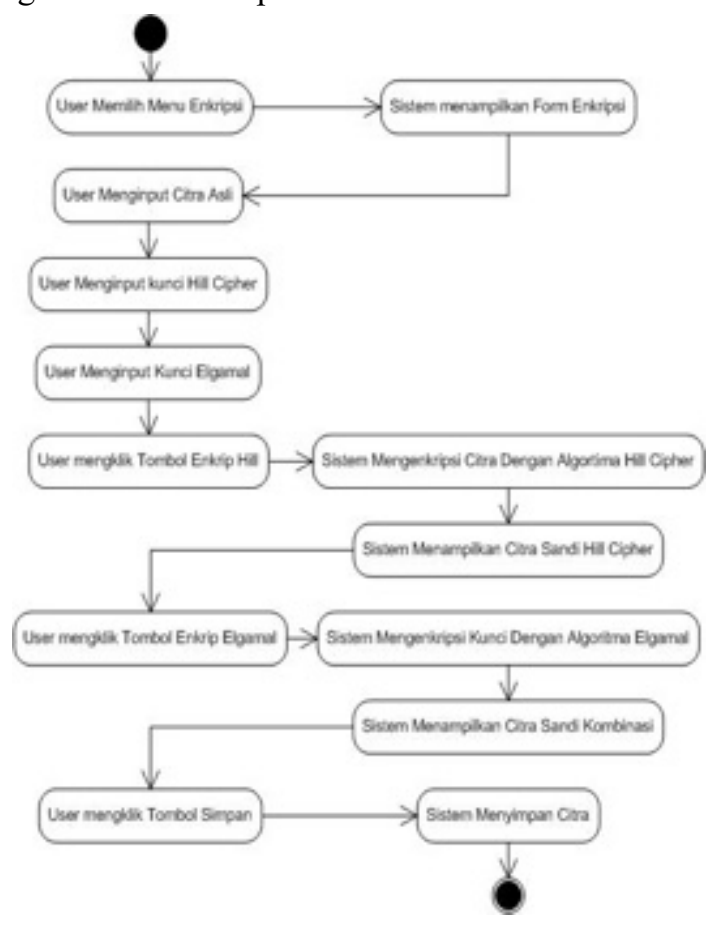

Gambar 4. Activity Diagram Enkripsi Citra

Menggambarkan aktivitas yang dilakukan pada saat melakukan enkripsi citra. 


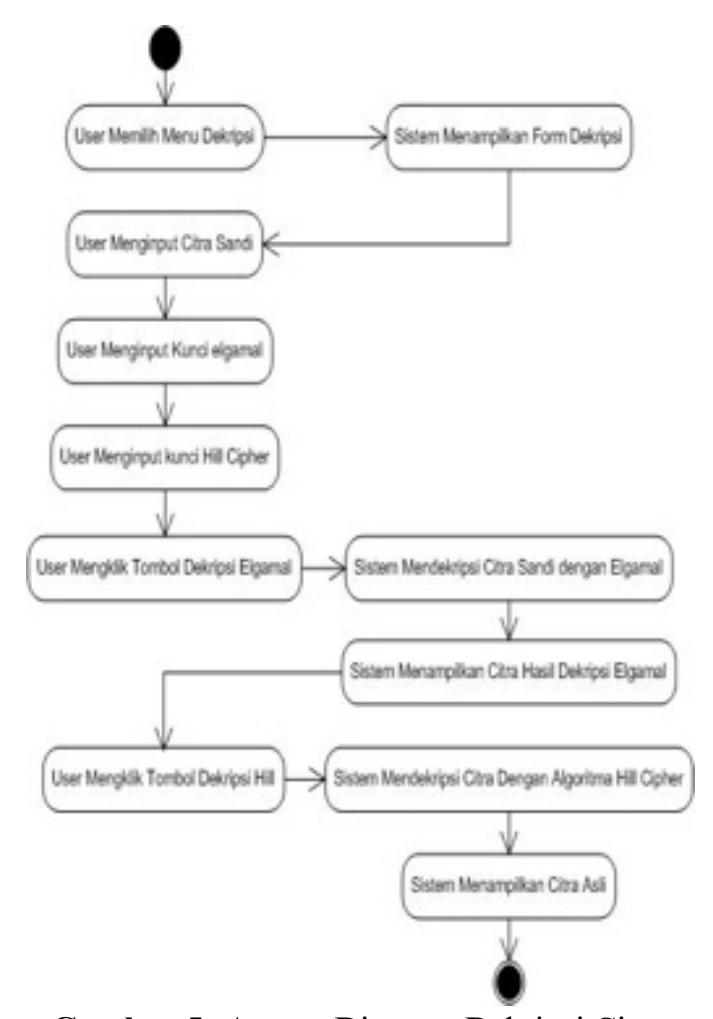

Gambar 5. Activity Diagram Dekripsi Citra

\section{HASIL DAN PEMBAHASAN}

Aplikasi pengamanan citra menggunakan metode Hill Cipher dan metode Elgamal.

\section{Tampilan Menu Utama}

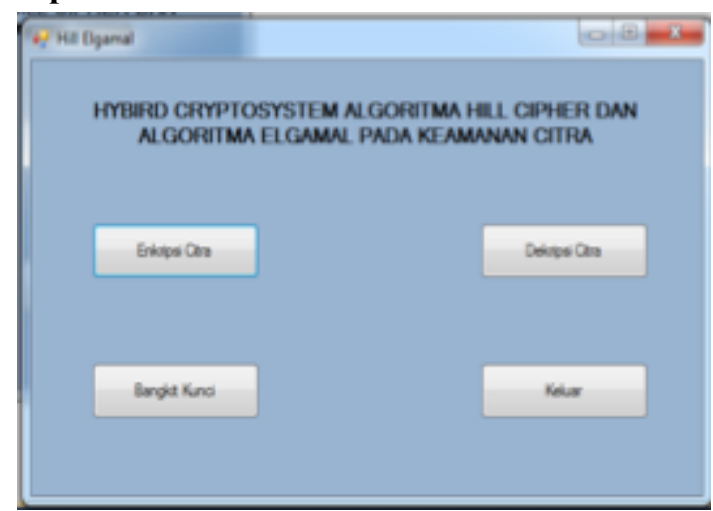

Gambar 6. Menu Utama

\section{Tampilan Menu Bangkit Kunci Citra}

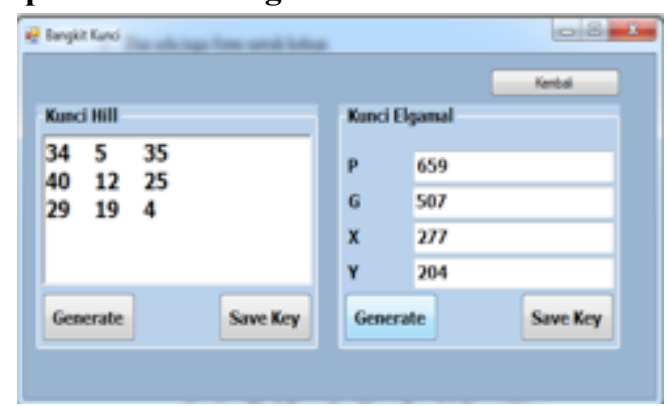

Gambar 7. Proses Pembangkitan Kunci 
Tabel 2. Hasil Uji coba Dekripsi Citra

\begin{tabular}{|c|c|c|c|}
\hline No. & Keterangan & Gambar & Waktu \\
\hline 1. & $\begin{array}{l}\text { Dekripsi citra } \\
\text { dengan } \\
\text { algoritma } \\
\text { elgamal. }\end{array}$ & 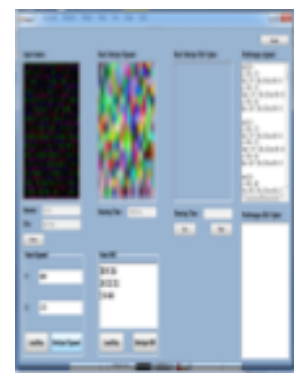 & $\begin{array}{l}11650.67 \\
\text { Milidetik }\end{array}$ \\
\hline 2. & $\begin{array}{l}\text { Dekripsi citra } \\
\text { dengan } \\
\text { algoritma hill } \\
\text { cipher. }\end{array}$ & 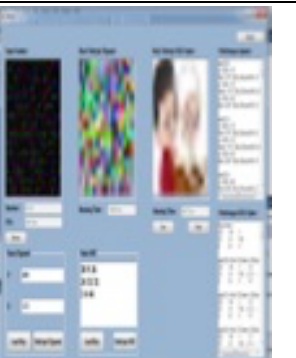 & $\begin{array}{l}4307.72 \\
\text { Milidetik }\end{array}$ \\
\hline
\end{tabular}

\section{KESIMPULAN}

Berdasarkan hasil perancangan dan pembuatan program aplikasi kriptografi menggunakan metode Hill Cipher dan Elgamal ini dapat di ambil kesimpulan sebagai berikut:

1. Dalam citra berhasil di terapkan dan mampu melakukan proses enkripsi dan dekripsi Semakin besar ukuran citra maka waktu proses enkripsi dan proses dekripsi akan membutuhkan waktu yang lebih lama, Hasil pengujian pada sistem di dapatkan bahwa citra yang telah mengalami proses enkripsi dan proses dekripsi dengan algoritma Hill Cipher dan Elgamal memiliki isi informasi yang sama dengan citra yang asli.

2. Pengamanan citra dengan menggunakan algoritma Hill Cipher dan Elgamal untuk merahasiakan citra berjalan dengan baik. citra berhasil di enkripsi dan di dekripsi, percobaan yang dilakukan pada algoritma Hill Cipher dan Elgamal, waktu proses yang di hasilkan dekripsi ciphertext lebih cepat dibandingkan hasil enkripsi plaintext.

\section{DAFTAR PUSTAKA}

Agung, H. (2016). Hybird Cryptosystem. Skripsi. Universitas Prima Indonesia, Medan.

Fauzi, A. dkk. (2017). Perancangan aplikasi keamanan pesan menggunakan algoritma elgamal dengan memanfaatkan algoritma one time pad sebagai pembangkit kunci. JTIK (Jurnal Teknik Informatika Kaputama), 1(1), 1-9.
Hasugian, A. H. (2013). Implementasi algoritma hill cipher dalam penyandian data. Pelita Informatika Budi Darma, 4(2), 115-122.

Jamaluddin, J., Zarlis, M., \& Tulus, T. (2018). Pengamanan Data dengan Kombinasi Teknik Kriptografi Rabin dan Teknik Steganografi Chaotic LSB. Prosiding SNASTIKOM 2014. STT Harapan. Medan

Ladjamudin, A. B. (2006). Analisis Desain Sistem Informasi. Yogyakarta: Graha Ilmu.

Pardede, A. M. H., \& Maulita, Y., (2014). Perancangan perangkat lunak enkripsi dan deskripsi file dengan metode transposisi kolom. Jurnal Kaputama, 8(1), 28-35.

Pardede, A. M. H. (2018). Aplikasi pengamanan file gambar menggunakan algoritma elgamal. Journal Information System Development (ISD), 3(2).

Putra, D. (2010). Pengolahan Citra Digital. Yogyakarta: Penerbit Andi.

Rini, B. (2011). Microsoft visual basic 2010 dan mysql untuk aplikasi point of sales. Yogyakarta: Wahana Komputer.

Sugiarti, Y. (2013). Analisis dan Perancangan UML (Unifed Modeling Language). Yogyakarta: Graha Ilmu.

Widyartono, A. (2011). Algoritma Elgamal Untuk Enkripsi Data Menggunakan Gnupg. Bandung: Informatika.

Widyanarko, A. (2019). Algoritma Hill Cipher. Yogyakarta: Graha Ilmu. 